\title{
Efeito da mitomicina-C tópica sobre os depósitos de colágeno total na submucosa das pregas vocais íntegras de suínos
}

\author{
Effect of topical mitomycin-C on total collagen deposits on the submucosa of \\ intact vocal folds in swine
}

Marcelo Charles Pereira ${ }^{1}$; João Carlos Domingues Repka²; Paulo Antonio Monteiro Camargo33; Daniel Zeni Rispoli, ACbC-PR4; Antônio Carlos Ligocki Campos, TCBC-PR ${ }^{5}$; Jorge Eduardo Fouto Matias ${ }^{6}$

R E S U M O

\begin{abstract}
Objetivo: Estudar o efeito da aplicação tópica de Mitomicina-C em diferentes concentrações sobre os depósitos de colágeno total na submucosa de pregas vocais íntegras de suínos. Métodos: Os animais foram divididos em três grupos de acordo com o conteúdo da solução tópica aplicada sobre as pregas vocais: solução fisiológica 0,9% (grupo controle); Mitomicina-C tópica $4 \mathrm{mg} / \mathrm{mL}$ (grupo 1); e Mitomicina-C $8 \mathrm{mg} / \mathrm{mL}$ (Grupo 2). Após 30 dias da aplicação, os animais foram submetidos à eutanásia, coletado amostras das pregas vocais e coradas pela técnica do picrosirius red com polarização para a quantificação computadorizada da deposição do colágeno, através do programa Image Pro plus 4.5Oे. Compararam-se as médias de área do colágeno depositado na submucosa das pregas vocais dos três grupos através do teste não paramétrico de Mann-Whitney. Resultados: As médias das áreas de depósito colágeno na submucosa das pregas vocais foram de 3.110,44 micrômetros quadrados $\left(\mathrm{mm}^{2}\right) ; 3.115,98$ mm² e 3.105,78 mm² nos grupos controle, 1 e 2 respectivamente. Não houve diferença significativa nas áreas de depósitos de colágeno total da submucosa das pregas vocais entre os três grupos estudados $(p>0,05)$. Conclusão: A mitomicina- $C$ aplicada topicamente em pregas vocais suínas íntegras não alterou significativamente a deposição de colágeno na submucosa.
\end{abstract}

Descritores: Cicatrização de feridas. Mitomicina. Cordas vocais. Colágeno. Suínos.

\section{INTRODUÇÃO}

A mitomicina-C é agente antimetabólico que inibe a proliferação do fibroblasto quando aplicado topicamente e tem sido utilizada frequentemente em modelos experimentais para reduzir a formação de cicatriz . Demonstrou-se que a mitomicina- $C$ tem sucesso quando utilizada experimentalmente para o tratamento da estenose subglótica e estenose glótica posterior, situações em que a cicatrização anormal e estenose foram moduladas e substituídas pelo retorno da mucosa de revestimento quando do uso tópico de mitomicina- $C^{2}$.

Estudos demonstram a eficácia da mitomicina-C em reduzir a formação da cicatriz e descrevem o seu mecanismo de ação pela inibição e bloqueio da síntese do DNA, prevenindo a proliferação do fibroblasto em área cirúrgica, fazendo com que haja menor formação de tecido cicatricial onde substância é aplicada ${ }^{2-4}$. Sua ação está ligada diretamente à sua concentração e ao tempo em que ela é mantida em contato com o ferimento ${ }^{5}$. Esse comportamento, de certa forma, leva a expectativa de que maiores concentrações e maior tempo de exposição possam causar maior efeito biológico.
Devido ao pequeno calibre da luz da laringe, o contato acidental da mitomicina-C em superfície mucosa de corda vocal íntegra pode ocorrer. Entretanto, não se observa, na literatura pertinente, estudos que relatassem as repercussões desse tipo de exposição.

O presente estudo teve como objetivo avaliar o efeito da aplicação tópica de mitomicina-C, em diferentes concentrações, sobre os depósitos de colágeno total na submucosa de pregas vocais íntegras de suínos.

\section{MÉTODOS}

Neste experimento foram utilizados nove suínos da raça larger white (Suideo Sus), obedecendo-se os princípios do Colégio Brasileiro de Experimentação Animal $(\mathrm{COBEA})^{6}$ e as recomendações para eutanásia de animais experimentais ${ }^{7,8}$. Os animais (quatro machos e cinco fêmeas), pesando entre $8.700 \mathrm{~g}$ e $11.562 \mathrm{~g}$ (média= $10.131 \mathrm{~g}$ ) e com idade entre 27 a 31 dias, foram avaliados clinicamente e considerados sadios dentro de distribuição normal de peso para a idade seguindo-se os padrões da EMBRAPA.

\footnotetext{
Trabalho realizado na Fazenda Experimental da Universidade Federal do Paraná e no Laboratório de Cirurgia Experimental do Programa de PósGraduação em Clínica Cirúrgica da Universidade Federal do Paraná - UFPR, Curitiba, PR, BR.

1. Mestrando do Programa de Pós-Graduação em Clínica Cirúrgica da Universidade Federal do Paraná - UFPR - BR; 2. Professor Adjunto do Departamento de Bioquímica da UniBrasil; 3. Doutorando do Programa de Pós-Graduação em Clínica Cirúrgica da UFPR - BR; 4 . Mestrando do Programa de Pós-Graduação em Clínica Cirúrgica da UFPR - BR; 5. Professor Titular do Departamento de Cirurgia - UFPR-BR; 6. Professor Adjunto do Departamento de Cirurgia - UFPR - BR.
} 
Os animais foram randomizados em três grupos de acordo com a solução a ser aplicada em ambas as cordas vocais de cada animal: grupo controle recebeu aplicação de algodão embebido em solução fisiológica 0,9\%; o Grupo 1, aplicação de algodão embebido em mitomicinaC na concentração de $4 \mathrm{mg} / \mathrm{mL}$; e o Grupo 2, aplicação de algodão embebido em mitomicina- $C$ na concentração de 8 $\mathrm{mg} / \mathrm{mL}$

\section{Aplicação tópica de mitomicina}

Todos os animais foram anestesiados recebendo como indução anestésica midazolam (DormonidÒ 1 mg/mL) na dose de $0,1 \mathrm{mg} / \mathrm{kg}$ por via IM; acepromazina $1 \%$ (AcepranOे 1\%) na dose de 0,1 mg/kg por via IM; ketamina (KetalarO $50 \mathrm{mg} / \mathrm{mL}$ ) na dose de $10 \mathrm{mg} / \mathrm{kg}$ por via IM; e atropina $0,5 \mathrm{mg} / \mathrm{mL}$ na dose de $0,06 \mathrm{mg} / \mathrm{kg}$ por via IM. A anestesia foi feita com PropofolÒ na dose de $6 \mathrm{mg} / \mathrm{kg}$ por via IV (veia auricular) e a manutenção com a mesma medicação na dose de 0,4mg/kg por via IV.

Depois de anestesiados os animais foram posicionados em decúbito dorsal, em proclive em mesa especial coberta por campo cirúrgico estéril. Para a retificação da laringe foi colocado cochim na região dorsal superior. Utilizou-se laringoscópio infantil (Microfrance ${ }^{\circledR}$ ) com angulação para comissura anterior e microscópio cirúrgico D. F. Vasconcelos 6700 com sistema de câmera acoplada para observação da glote e colocação de algodão embebido nas soluções específicas de cada grupo (Figura 1). Após exposição e visualização da mucosa da borda livre do terço anterior da prega vocal direita e esquerda, colocou-se aí uma bola de algodão de aproximadamente $3 \mathrm{~mm}$ de diâmetro no seu maior eixo, embebida com a solução de mitomicina-C a $4 \mathrm{mg} / \mathrm{mL}$, no grupo 1 e $8 \mathrm{mg} / \mathrm{mL}$ no grupo 2 , envolvendo ambas as pregas vocais durante três minutos cronometrados. No grupo controle repetiu-se o mesmo processo descrito anteriormente com algodão embebido em soro fisiológico. Após os três minutos, retirava-se o algodão e limpava-se a região com soro fisiológico 0,9\%.

Após a recuperação anestésica, os suínos foram recolocados em pocilgas, onde voltaram a receber água e ração 12 horas após o procedimento.

A eutanásia dos animais realizou-se 30 dias após a aplicação endoscópica da mitomicina-C. Os animais foram submetidos ao mesmo protocolo pré-anestésico e anestésico utilizado anteriormente seguido de eletrocussão. Toda a laringe do animal foi retirada para a melhor coleta da prega vocal (Figura 2). Realizou-se incisão longitudinal anterior na laringe para expor a região das pregas vocais e realizar incisão rente à cartilagem tireóide para a retirada da prega vocal e preservação da cobertura mucosa. A peça foi fixada com alfinetes sobre um retângulo de papel cartão identificando-se o animal, o lado (direito ou esquerdo) da prega vocal, bem como a região anterior da prega vocal. Posteriormente, este retalho foi fixado em formol a $10 \%$. Após período de fixação de 24 horas, utilizando-se lâmina histológica sobre tábua de macroscopia, foram retiradas duas amostras retangulares e acondicionadas em cápsula histológica e colocadas no autotécnico (Leica ${ }^{\circledR}$ mo- delo RM 2145) para processamento "overnight", sendo desidratadas em concentrações crescentes de álcool etílico a 70, 80 e 90\%. Posteriormente, foram diafanizadas em xilol contendo misturas sequencialmente concentradas de parafina durante 12 horas. Realizada inclusão em parafina quente (Leica ${ }^{\circledR}$ modelo EG 1160), os blocos foram microtomizados (Leica ${ }^{\circledR}$ modelo RM 2145) em cortes de 5 ìm e dispostos em lâmina de vidro de $75 \times 25$ mm, realizandose dois níveis de corte para cada área.

No estudo histológico empregou-se coloração pela solução de Picrosirius Red com polarização, onde a substância não-colágena corou-se em preto e o colágeno em amarelo, vermelho alaranjado e vermelho. Estas cores foram selecionadas através do programa para quantificação e somatória da área selecionada em micrômetros quadrados. A leitura das lâminas foi realizada sempre em triplicata através do programa Image Pro plus $4.5^{\circledR}$ para Windows ${ }^{\circledR}$ em um microcomputador acoplado à microscópio Olympus ${ }^{\circledR}$ BX50 e câmera de vídeo Sony ${ }^{\circledR}$, calibrado previamente em micrômetros com objetiva de 20 vezes (Figura 3). As medidas foram transferidas para o programa Excel Windows ${ }^{\circledR} \mathrm{e}$ colocados em tabela para análise estatística.

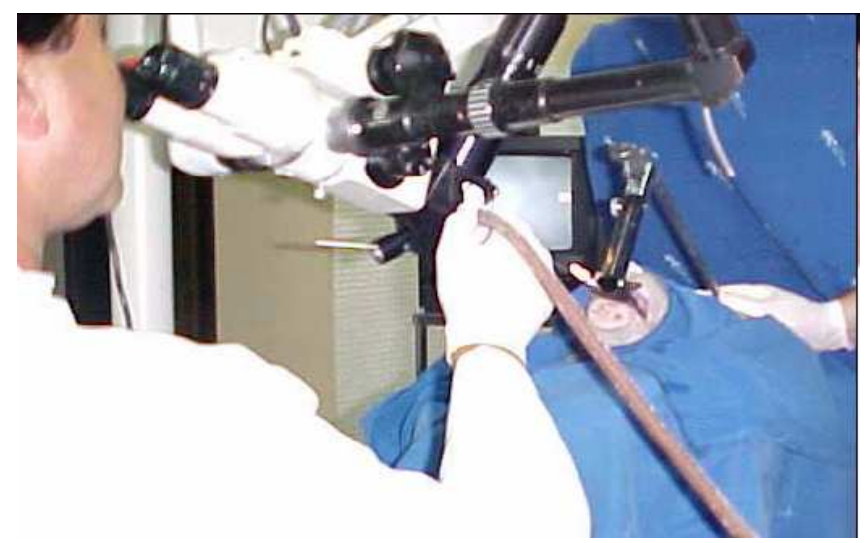

Figura 1 - Técnica da aplicação endoscópica de Mitomicina-C na superfície das pregas vocais utilizando microscópio cirúrgico em animal anestesiado com laringoscópio infantil aplicado.

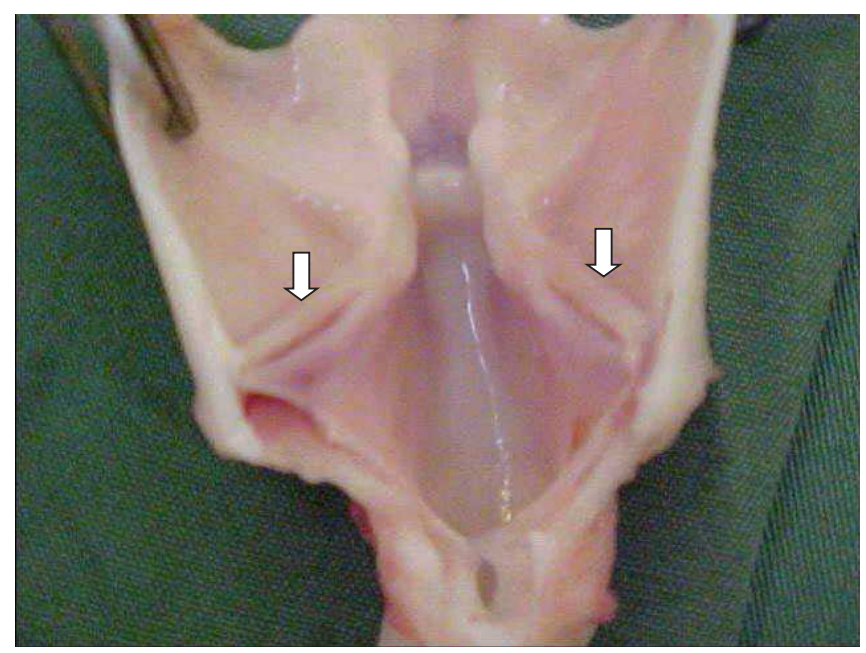

Figura 2 - Espécime (laringe) ressecada em bloco para amostragem das cordas vocais (setas) na sequência. 


\section{Análise estatística}

Nesta pesquisa foram estimados três grupos, compostos de três animais cada grupo e de seis pregas vocais por grupo, cada prega analisada em triplicata. O resultado avaliado neste estudo quantificou em micrômetros quadrados $\left(\mathrm{mm}^{2}\right)$ o colágeno total na submucosa das pregas vocais. Quando realizadas comparações de resultados em grupos diferentes relativas às diferenças de quantidade de colágeno, considerou-se o teste não paramétrico de MannWhitney. Em todas as comparações efetuadas, a hipótese nula correspondeu a resultados iguais nos grupos de comparação e a hipótese alternativa, a resultados diferentes. Em todos os testes, nível de significância de $5 \%(p=0,05)$ foi considerado estatisticamente significante.

\section{RESULTADOS}

Não foram observadas sinéquias em nenhuma das laringes examinadas após a eutanásia.

As médias e desvios-padrão das áreas aferidas para os depósitos de colágeno na submucosa das pregas vocais de cada grupo de animais do estudo são mostradas

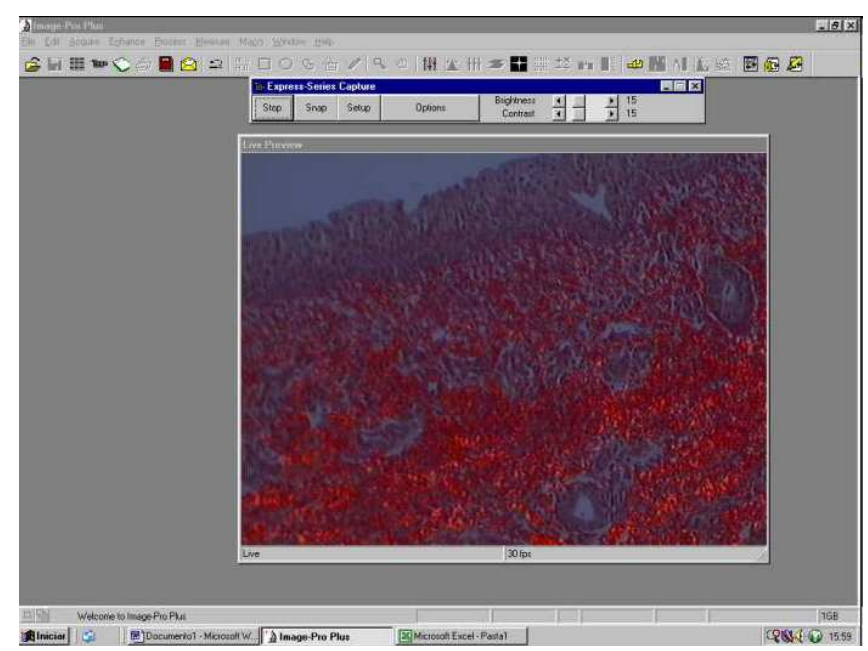

Figura 3 - Imagem da área de trabalho do programa Image Pro Plus ${ }^{\circledR}$ para análise (cálculo) da área de superfície do corte com presença de fibras colágenas (coloração pelo picrosirius red). na tabela 1. No grupo controle (animais submetidos à aplicação de solução fisiológica 0,9\% tópica) a média da área do colágeno depositado na submucosa das pregas vocais foi de 3.110,44 micrômetros quadrados. No grupo 1 (animais submetidos à aplicação de mitomicina-C tópica na concentração de $4 \mathrm{mg} / \mathrm{mL}$ ) a média da área do colágeno depositado na submucosa das pregas vocais foi de 3.115,98 micrômetros quadrados. No Grupo 2 (animais submetidos à aplicação de mitomicina-C tópica na concentração de $8 \mathrm{mg} / \mathrm{mL}$ ) a média da área do colágeno depositado na submucosa das pregas vocais foi de 3.105,78 micrômetros quadrados.

Não houve diferença significativa entre as medidas das áreas de depósito de colágeno total entre os grupos de estudo ( 1 e 2 ) e o grupo controle. As médias das áreas de depósito de colágeno total nos dois grupos de estudo também não foi estatisticamente diferentes.

\section{DISCUSSÃO}

Em estudo previamente realizado ${ }^{4}$ com o mesmo modelo atualmente empregado, onde investigou-se o efeito da mitomicina- $C$ tópica sobre a área cruenta de ressecção de fragmento de prega vocal com laser de $\mathrm{CO}_{2}$, constatou-se ser praticamente impossível o controle adequado do uso absolutamente seletivo da mitomicina- $\mathrm{C}$ em uma cavidade tão pequena como a laringe. Apesar do maior esmero cirúrgico, o contato do quimioterápico com a prega vocal contralateral acabava por ocorrer. Interrogou-se, portanto, se os efeitos já descritos na literatura do uso tópico da mitomicina-C sobre os depósitos de colágeno em pregas vocais operadas se repetiriam, desta feita, em cordas vocais anatomicamente íntegras em seu revestimento mucoso e desprovidas por completo de qualquer processo inflamatório agudo ou crônico.

Vários modelos animais têm sido propostos para estudos experimentais que envolvam tópicos em cirurgia endolaríngea. Garrett et al, em 2000, comparou pregas vocais de cão, porco e macaco, observando a quantidade da deposição do colágeno, fibras de elastina e tecido amorfo 9 . Concluiu que a prega vocal do porco e do cão são similares à do homem quanto à quantidade de elastina e de colágeno, além de apresentarem um plano de dissec-

Tabela 1 - Quantificação do colágeno depositado na submucosa das cordas vocais nos grupos estudados.

\begin{tabular}{lccc}
\hline Grupos & $\begin{array}{c}\text { Área da deposição do colágeno } \\
\text { total }\left(\mathrm{mm}^{2}\right) \text {. Média + Desvio-padrão }\end{array}$ & $\begin{array}{c}\text { Comparação estatística } \\
\text { c/ Grupo Controle }(\mathbf{p})\end{array}$ & $\begin{array}{c}\text { Comparação estatística } \\
\text { Grupo } 1 \times 2(p)\end{array}$ \\
\hline $\begin{array}{l}\text { Grupo Controle } \\
\text { (Sol. Salina 0,9\%) }\end{array}$ & $3.110,44+340,66$ & - & - \\
$\begin{array}{l}\text { Grupo1 } \\
\text { (MMC 4mg/mL) }\end{array}$ & $3.115,98+279,91$ & 0,9156 & - \\
$\begin{array}{l}\text { Grupo 2 } \\
\text { (MMC 8mg/mL) }\end{array}$ & $3.105,78+308,28$ & 0,9230 & - \\
\hline
\end{tabular}

$M M C=$ Mitomicina- $C ; m^{2}=$ micrômetro quadrado; $m g / m L=$ miligramas por mililitro 
ção do microflap similar ao do homem. No presente estudo, o delineamento experimental exigia um animal de médio porte com pregas vocais semelhantes às do homem, sem a necessidade da observação da função por videolaringoestroboscopia, quando neste caso o cão seria o melhor modelo de estudo da função da prega vocal por apresentar a fase vertical da onda mucosa vista na videolaringoestroboscopia - o que não é visualizado no porcos.

A mitomicina-C tópica tem sido empregada em número crescente de situações onde se deseja controlar efetivamente o processo cicatricial que se instala após a manipulação cirúrgica de pregas vocais ${ }^{2,10-13}$. Entretanto, apesar de evidências experimentais demonstrando quantidades significativamente menores de colágeno total em pregas vocais operadas e tratadas com mitomicina- $\mathrm{C}^{1,4,14-}$ ${ }^{17}$, não há relatos clínicos ou experimentais na literatura de efeito similar ou não do uso da mitomicina-C em cordas vocais íntegras.

Em condições experimentais muito similares as do estudo atual, pôde-se demonstrar redução significativa da área total de colágeno depositado em prega vocal com ressecção parcial de borda livre e tratada com mitomicina-
C tópica, na concentração de $0,4 \mathrm{mg} / \mathrm{mL}$, quando comparada à pregas vocais com operação idêntica, porém sem aplicação tópica do quimioterápico 4 .

Já na atual pesquisa, quando aplicou-se mitomicina- $C$, mesmo com concentrações superiores $(4 \mathrm{mg} /$ $\mathrm{mL}$ e $8 \mathrm{mg} / \mathrm{mL}$ ) sobre a superfície íntegra de pregas vocais anatomicamente hígidas, não houve diferenças nas áreas calculadas de depósito de colágeno total comparadas aos controles (Tabela 1). Tais achados sugerem ação seletiva local da mitomicina- $C$ sobre tecidos com injúria e em fase de cicatrização, corroborando com a hipótese de que o revestimento mucoso íntegro das pregas vocais não manipuladas cirurgicamente e desprovidas de áreas cruentas, previne o efeito antimetabólico da mitomicina-C sobre os depósitos submucosos de colágeno total.

Em função dos resultados obtidos neste experimento, pôde-se concluir que a mitomicina-C - apesar de seu efeito inibidor já descrito sobre metabolismo do colágeno total da submucosa de pregas vocais com áreas cruentas e/ou em cicatrização -, é incapaz de reproduzir tal efeito quando aplicada em pregas vocais íntegras mesmo em concentrações muito superiores àquelas terapêuticas preconizadas na literatura.

\title{
A B S T
}

\begin{abstract}
Objectives: To compare the effects of topical mitomycin- $C$ at different concentrations on submucosal collagen deposition on the vocal folds of swine. Methods: The animals were divided into three groups according to the composition of the topical solution to be applied to the vocal folds: $0.9 \%$ saline solution (control group); $4 \mathrm{mg} / \mathrm{ml}$ mitomycin-C (group 1) and $8 \mathrm{mg} / \mathrm{ml} \mathrm{mitomycin-C} \mathrm{(Group}$ 2). Thirty days after the application, all animals were sacrificed, their vocal folds were collected and stained by the picrosirius red technique, and submucosal collagen deposition areas were estimated by the Image Pro Plus $4.5^{\circledR}$ software. Mann-Whitney test was used to compare differences between parameters of each group. Results: The means of the areas of submucosal collagen deposits on vocal folds were 3110.44 square micrometers $\left(\mu \mathrm{m}^{2}\right), 3115.98 \mu \mathrm{m}^{2}$ and $3105.78 \mu \mathrm{m}^{2}$ for groups control, 1 and 2, respectively. There were no statistical differences across the three groups $(p>0.05)$. Conclusion: Mitomycin- $C$ topically applied to intact vocal folds of swine did not alter submucosal collagen deposition.
\end{abstract}

Key words: Wound healing. Mitomycin. Vocal cords. Collagen. Swine.

\section{REFERENCIAS}

1. Garrett CG, Soto J, Riddick J, Billante CR, Reinisch L. Effect of mitomycin- $C$ on vocal fold healing in a canine model. Ann Otol Rhinol Laryngol. 2001; 110(1):25-30.

2. Eliashar R, Eliashar I, Esclamado R, Gramlich T, Strome M. Can topical mitomycin prevent laryngotracheal stenosis? Laryngoscope. 1999; 109(10):1594-600.

3. Ihnat MA, Lariviere JP, Warren AJ, La Ronde N, Blaxall JR, Pierre $\mathrm{KM}$ et al. Suppression of P-glycoprotein expression and multidrug resistance by DNA cross-linking agents. Clin Cancer Res. 1997; 3(8):1339-46.

4. Camargo PAM, Campos ACL, Matias JEF, Rispoli DZ, Przysiezny PE, Fonseca VR. Efeito da mitomicina C tópica na cicatrização de prega vocal em modelo suíno. Rev Bras Otorrinolaringol. 2006; 72(5):601-4.

5. Ward RF, April MM. Mitomycin-C in the treatment of tracheal cicatrix after tracheal reconstruction. Int J Pediatric Otorhinolaryngol. 1998; 44(3):221-6.

6. C.O.B.E.A. Colégio Brasileiro de Experimentação Animal. Princípios éticos na experimentação animal. In: Congresso do Colégio Brasileiro de Experimentação Animal; São Paulo; 1991.
7. Close B, Banister K, Baumans V, Bernoth EM, Bromage N, Bunyan $J$ et al. Recommendations for euthanasia of experimental animals: Part 2. DGXT of the European Commission. Lab Anim. 1997; 31(1):1-32.

8. Raymundo MM, Goldim JR. Ética da pesquisa em modelos animais. Revista de Bioética e Ética Médica: Conselho Federal de Medicina. Brasília. 2002; 10(1):31-42.

9. Garrett CG, Coleman JR, Reinisch L. Comparative histology and vibration of the vocal folds: implications for experimental studies in microlaryngeal surgery. Laryngoscope. 2000; 110(1):814-24.

10. Spector JE, Werkhaven JA, Spector NC, Huang S, Page RN, Baranowski $B$ et al. Preservation of function and histologic appearance in the injured glottis with topical mitomycin-C. Laryngoscope. 1999; 109(7 pt 1):1125-9.

11. Hartnick CJ, Hartley BE, Lacy PD, Liu J, Bean JA, Willging JP et al. Topical mitomycin application after laryngotracheal reconstruction: a randomized, double-blind, placebo-controlled trial. Arch Otolaryngol Head Neck Surg. 2001; 127(10):1260-4.

12. Ribeiro FAQ, Borges JP, Zaccbi FFS, Guaraldo L, Eckley CA. Clinical and histological healing of surgical wounds treated with mitomycin C. Laryngoscope. 2004; 114(1):148-52. 
13. Roh $J$, Yoon YH. Prevention of anterior glottic stenosis after transoral microresection of glottic lesions involving the anterior commissure with mitomycin C. Laryngoscope. 2005; 115(6):10559.

14. Correa AJ, Reinisch L, Sanders DL, Huang S, Deriso W, Duncavage JA, Garrett CG. Inhibition of subglottic stenosis with mitomycin-C in the canine model. Ann Otol Rhinol Laryngol. 1999; 108(11 Pt 1):1053-60.

15. Gray SD, Tritle N, LI W. The effect of mitomycin on extracellular matrix proteins in a rat wound model. Laryngoscope. 2003; 113(2):237-42.

16. Roh JL, Yoon YH. Prevention of anterior glottic stenosis after bilateral vocal fold stripping with mitomycin C. Arch Otolaryngol Head Neck Surg. 2005; 131(8):690-5.

17. Fang $R$, Sun J, Wang G, Sun D. Comparison between mitomycin C and chitosan for prevention of anterior glottic steno after $\mathrm{CO}_{2}$ laser cordectomy in dogs. Laryngoscope. 2007; 117(11):2057-62.
Recebido em 12/10/2008

Aceito para publicação em 17/12/2008

Conflito de interesse: nenhum

Fonte de financiamento: nenhuma

\section{Como citar este artigo:}

Pereira MC, Repka JCD, Camargo PAM, Rispoli DZ, Campos ACL, Matias JEF. Efeito da mitomicina C tópica sobre os depósitos de colágeno total na submucosa das pregas vocais íntegras de suínos. Rev Col Bras Cir. [periódico na Internet] 2009; 36(3). Disponível em URL: http:// www.scielo.br/rcbc

\section{Endereço para correspondência:}

Jorge Eduardo Fouto Matias

jefmatias@ufpr.br 